\title{
EDITORIAL
}

\section{Letter from America: acute in-patient psychiatry bed shortages}

\author{
Steven S. Sharfstein
}

Steven S. Sharfstein is President and Chief Executive Officer of Sheppard Pratt Health System in Baltimore, Maryland, and Vice Chair, Department of Psychiatry, University of Maryland, USA. Correspondence Professor Steven S. Sharfstein, MD, Sheppard Pratt Health System, 6501 N. Charles Street, Baltimore, MD 21204, USA. Email: ssharfstein@sheppardpratt. org

\begin{abstract}
SUMMARY
The number of in-patient beds for psychiatric treatment in America has declined dramatically over the past 40 years. Public and private policies have encouraged an extremely short-term, crisisstabilisation model of treatment. This is true on both general and subspecialty units. As a result, readmissions have increased, emergency rooms are crowded, and many patients end up homeless or incarcerated in the criminal justice system. These changes have created a public health crisis in America, and are the greatest challenges that American psychiatry faces today.

\section{DECLARATION OF INTEREST}

None.
\end{abstract}

'America's mental health system is in shambles' - so said the letter to President Bush from the Presidential New Freedom Commission on Mental Health (New Freedom Commission on Mental Health 2003). The report, published in 2003, is an excellent description of the disjointed policies and reforms of the past 30 years that created the 'patchwork relic' (their words) that is the current US mental healthcare system. Although the report primarily focuses on out-patient community-based services, evidence-based care and 'recovery' as overriding themes for providers and 'consumers' (the American term for service users), it also alerted the field to the potential shortage of acute in-patient services and its contribution to the nonsystem in America today.

In-patient psychiatric beds in America have declined drastically over the past four decades. Numbers have fallen in both public and private settings, a trend driven primarily by public (mostly state) budgets and private insurance companies after the implementation of managed care utilisation review (Box 1). The dramatic declines in length of stay have been informed, to a lesser extent, by growing consensus on appropriate clinical practice in hospitals and concerns about civil liberties.

\section{From asylum care...}

The peak of public asylum psychiatry in the USA occurred in the mid-1950s, with 550000 patients in state and county mental hospitals. With the advent of antipsychotic medications, these numbers began to decline. By 1970, slightly more than 400000 psychiatric beds remained in these public settings. By 2002, the total number of beds had declined to 212000 , with only $27 \%$ (57240 beds) provided by state and county mental hospitals. Deinstitutionalisation since 1970 has been dramatic and all-encompassing, mostly driven by financial incentives to cut costs and shift payments from the state to the federal treasury. The decrease in public beds was compensated somewhat by an increase in beds provided through general hospital psychiatric units and, to a lesser extent, private psychiatric hospitals. In 1990, just over 50000 beds were provided through units in general hospitals and 45000 by private psychiatric hospitals. However, primarily because of managed care utilisation review, these bed numbers had fallen to 40000 in general hospitals and fewer than 25000 in private psychiatric hospitals by 2005 (Sharfstein 2009).

\section{...to acute admissions}

At the same time, emergency department visits for mental disorders increased from 1.4 million visits in 1990 to nearly 2.5 million in 2003.

Today in America, an acute psychiatric admission primarily occurs in general hospital units or a private psychiatric hospital. Length of stay is quite short, averaging 4-10 days on most units and 1014 days on subspecialty units. Patients are rapidly stepped down to day programmes, intensive outpatient and community-based psychiatric rehabilitation services and residential alternatives.

B0X 1 Managed care utilisation review

Most psychiatric treatment paid by insurance in the USA is 'managed' by a private company that must approve continued stays in hospital or additional out-patient visits according to medical necessity criteria developed by the company. This most often requires a telephone review session between the reviewer (which could be a nurse or social worker) and the treating psychiatrist. For in-patients this may take place on a daily basis. 


\section{The problem of readmissions}

Readmissions have also increased. A recent study of re-hospitalisation, published in the New England Journal of Medicine, found that $24.6 \%$ of patients with psychosis were re-hospitalised within 30 days, the second highest rate of re-hospitalisation for all psychiatric diagnoses in America (Jencks 2009). Patients spend many hours or days in emergency rooms, overcrowding a vital area of the healthcare system. In addition, there is a public health crisis related to the many thousands of seriously mentally ill patients who are homeless or incarcerated in US jails and prisons.

To many of us, it is clear that the pendulum towards community-based services has swung too far, that many individuals who should be treated in hospitals are not, that length of stay is often too short to adequately treat an episode of psychosis or other acute psychiatric emergency, and that the cost of the government's policies and programmes has been considerably high but shifted to areas other than the healthcare system, such as criminal justice, social welfare and families.

These days, 'hospital treatment' can be considered an oxymoron. What occurs in the hospital can be more accurately described as crisis stabilisation. A 'medically necessary' admission (the managed-care term) must include evidence of dangerousness due to suicide or homicide (such as harmful acts to self or others) or grossly impaired self-care. Concerns about safety are paramount, and this is what leads to admission. Civil liberty issues are also an important concern with these admissions because as many as one-third are involuntary. Legal expectations and constraints, however, lead to a legal review of each patient admitted to hospital involuntarily within a few days of admission and often result in discharge if the dangerousness criteria are not met.

\section{The crisis stabilisation model}

So, how do we function on the acute in-patient unit in America within these economic, regulatory, and legal constraints?

Hospital care is conceptualised as a six-step process, the crisis stabilisation model. The first step entails the definition of a focal problem, answering the question, 'Why is the patient here at this moment?' Within the first 24 hours, a discrete set of objectives must be established, which ideally should meet those of the patient and their family. The second step is to make a correct diagnosis, as the reason for admission is often an inadequate understanding of the primary diagnosis and associated comorbidities. The third is the formulation of goals for the hospitalisation from day one that relate to the aftercare plans. The fourth is determining which treatments to use, including the various biological interventions (such as medication changes or additions) that require prompt intervention as well as the psychosocial treatments that can be initiated in the in-patient setting and continued as the patient steps down to out-patient treatment. The fifth step is to work from day one with the patient's family or other support system to provide a bridge to the outside. The sixth is to establish the out-patient treatment and to try to make sure that those connections are made once the patient is discharged.

There is an increasing trend in America to create subspecialty units that again focus on the crisis stabilisation model but within a given psychiatric subspecialty, such as geriatrics, paediatrics, adolescents, dual diagnosis (mental illness/substance use, mental illness/developmental disabilities), eating disorders, trauma and forensics. These specialty units often have a longer length of stay than the general acute unit.

\section{Is the American model working?}

It is my assessment that approximately half of the admissions to psychiatric beds are well handled within this paradigm of very short stays and prompt discharge with out-patient care. The other half, however, are often discharged acutely ill and are at risk of rapid re-hospitalisation, which is certainly wasteful and contrary to the best interest of the patient and the family.

There is some small evidence that the downward trend in psychiatric bed numbers may be reversing. The past 2 years have actually seen an addition of beds in public hospitals after a nearly 50year decline, and beds have also been added in private psychiatric facilities and general hospitals. A return to the prior era of long hospital stays, especially in the public sector, however, is not possible. So, we continue to refine and try to make the acute in-patient stay more effective, linked to and coordinated with a community-based system of care. That is one great challenge in American psychiatry today.

\section{References}

Jencks SF, Williams MV, Coleman EA (2009) Rehospitalizations among patients in the Medicare fee-for-service program. New England Journal of Medicine; 14: 1418-28.

New Freedom Commission on Mental Health (2003) Achieving the Promise: Transforming Mental Health Care in America. Final Report. New Freedom Commission on Mental Health.

Sharfstein SS, Dickerson FB, Oldham JM (eds) (2009) Textbook of Hospital Psychiatry. American Psychiatric Press. 